\title{
CULTURAL SCIENCE
}

\section{ART THERAPY IN SPACE OF MODERN CULTURE ABSTRACT}

\section{Davtyan Vardan ${ }^{1}$}

\section{Abstract}

Art therapy is the softest and at the same time the deepest method in the arsenal of psychologists and psychotherapists. It is associated with the disclosure of creative opportunities and the identification of hidden reserves of an individual. As a result, people find effective ways of the solution of their difficulties. Art therapy is a path leading to the depths of the psyche. By depicting the problem and mood through the drawing, modeling or writing description, a person as if receives an encrypted message from his subconsciousness. A man can solve many problems on his own, become his own psychologist, assess his own mental states, the manifestation of emotions, appropriately managing his own behavior.

Key words: art therapy modern types, art, origami.

doi: http://doi.org/10.15350/F_7/10

Искусство как терапевтический метод дает выход внутренним эмоциям, конфликтам, помогает интерпретировать вытесненные желания и переживания, повышает самооценку личности, развивает творческие способности. Искусство это не только мастерство и техника построения образа, но и, в первую очередь, отражение личности творца в художественном произведении. Именно эта мысль положена в основу работы психолога, применяющего технику арт-терапии. Человек творит: рисует, гравирует, пишет, - выражая свой внутренний мир, свои осознанные и неосознанные стремления. Некоторые психологи считают, что терапевтическое воздействие оказывают по-настоящему хорошие произведения искусства, носителями истины, добра и красоты являются произведения искусства, которые имеют высокую художественную ценность. Поэтому человек должен стремиться выразить свои душевные состояния в хорошо выполненной картине, хорошо написанном эссе и т.д.

Другим возможным механизмом является то, что творческий процесс можно рассматривать как исследование реальности, обнаружение еще нераскрытого нового. На ранних стадиях своего развития в арт-терапии отражались психоаналитические воззрения, согласно которым художественная деятельность клиента рассматривалась как неосознанное выражение психических процессов. Привлекательность арт-терапии в главном для современного человека состоит в том, что данный способ в главном употребляет невербальный метод общения и самовыражения. В процессе творчества деятельно задействуется правое полушарие мозга. Сегодняшняя же культура использует основным образом вербальную си-

\footnotetext{
${ }^{1}$ Davtyan Vardan, Graduate student, Departments of Theory and History of Culture, FSEI HPE of the St. Petersburg Institute of Culture and Arts, Russia.
} 
стему общения и левое «логическое» полушарие. Природное, гармоничное развитие человека имеет необходимость в одинаковом формирование двух полушарий и обычное межполушарное взаимодействие. Арт-терапия основывается на внутренние, самоисцеляющие ресурсы человека, тесновато связанными с его креативными способностями.

В креативных работах, как правило, отражены методы взаимодействия с природой. Переживая образы, человек обретает собственную целостность, неповторимость и особенность. Еще, разрешено использовать другие формы художества - театральные постановки, импровизации, литературное творчество. Таким образом, достигаются следующие цели [1]:

1) Дать социально приемлемый выход агрессии и другим негативным эмоциям;

2) Облегчить процесс психорегуляции, поскольку внутренние неосознанные конфликты и страдания часто легче выразить через образные формы, чем в ходе вербального общения.

3) Получить материалы для интерпретации и диагностики.

4) Проработать привычные для пациента мысли и чувства.

5) Сгладить отношения между психологом и пациентом. Совместное участие психолога и пациента в художественном творчестве будет способствовать развитию эмпатии и взаимопонимания.

6) Развивать чувство внутреннего контроля.

7) Сосредоточить внимание на ощущениях.

Участие в творческой деятельности создает большие возможности для проверки кинестетических и визуальных ощущений.

8) Развивать художественные навыки и повысить самооценку.

Инновационная научная арт-терапия, как это не удивительно, при всем своем многообразии взаимосвязей с культурными прецедентами теснее всего стоит к варварскому, «простому» старейшему художеству. Оно, как и арт-терапия базируется на неожиданном самовыражении и пренебрегает все эстетические аспекты в оценке его итогов и мастерства создателя. Поэтому как, наиболее важен процесс творчества, а не итог.

В арт-терапии принципиальным мнением считается сублимация - представление желаний и машинальных инстинктов (время от времени деструктивных) с поддержкою трансформирования их в творения художества. Художество имеет возможность «навести и в иное русло» и проявить эти ощущения как: злоба, болезнь, тревогу, ужас.

Преимущественные стороны метода арт-терапии [2]:

1.Отчуждает вероятность для выражения брутальных эмоций в общественно - применимой стилю. Живопись, живописание красками либо лепка считаются не опасными методами разрядки напряжения;

2.Убыстряет успех терапии. Личные волнения и подсознательные инциденты свободнее выражаются с поддержкою зрительных образов, нежели в беседе (вербальной психотерапии). Невербальные виды общения имеют все шансы с большей возможностью избежать намеренной цензуры;

3.Дает причины для диагностической работы и интерпретации в процессе терапии. Творческая продукция сообразно фактору ее действительности не имеет возможность отказываться больным. Манера художественной работы и ее оглавление предоставляют терапевту грандиозную информацию, не считая такого, сам создатель имеет возможность привнести взнос в интерпретацию собственных личных творений;

4.Дает вероятность действовать с эмоциями и думами, которые кажутся непреодолимыми (гибель, утраты, перенесенное принуждение и травмы, внутрен- 
ние инциденты, ужасы, мемуары из юношества, сны). Время от времени невербальное лекарство как оказалось единым инвентарем, разрезающим и проясняющим функциональные впечатления и убеждения;

5.Содействует укреплению терапевтических отношений. Единые элементы в художественном творчестве членов категории имеют все шансы убыстрить формирование позитивных эмоций и эмпатий;

6.Способствует выходу в свет ощущения внутреннего конроля;

7.Производит и увеличивает интерес к эмоциям;

8.Увеличивает чувство своей личной ценности, усиливает художественный профессионализм. Итоговым продуктом терапии художеством считается довольство, образующаяся в итоге раскрытия укрытых умений и их становления.

В числе современных средств и направлений в арт-терапии все ярче и ярче говорит о себе, такое многообещающее направление как - оригами.

Оригами - обычное японское искусство, проектирование разных бумажных фигурок способом складывания квадрата в отсутствии вырезания и слипания. Это художество все более интегрируется в мировую культуру, делается предметом исследования профессионалов таковых сфер, как проектирование, математика, структура, промышленный дизайн, фактическая психология, педагогика, и арт-терапия. В данный момент, оригами как способ арт-терапии с фуррором употребляют в реабилитационной и целебной практике врача самых различных квалификаций. Очень много исследований говорят о том, что занятия оригами облагораживают свойство жизни нездоровых, подсобляют забыть болезнь и несчастье, увеличивают самооценку, убавляют степень тревожности, содействуют налаживанию дружественных взаимоотношений, взаимопомощи в коллективе, подсобляют определить контакт между больным и доктором. Потому, в арт-терапевтической практике возникает новейший термин - «образ жизни оригами».

Занимаясь оригами, клиент принимает участие в захватывающем деянии превращает бумажный квадрата в необычную фигуру - цветочек, бабочку, динозавра, коробочку. Данный процесс припоминает фокус-покус, маленькое понятие, что постоянно вызывает удовлетворенное изумление. Возникает желание представить кому-нибудь это волшебство, изготовить что-то еще. Теряется эмоция обособленности, налаживается обращение, в том количестве и больного с доктором, что считается в особенности принципиальным, когда клиент - малыш. Время от времени бывают случаи, когда детки, в состоянии волнения, ужаса отрешаются воспринимать медикаменты либо пищу. Тогда на содействие прибывает арт-терапевт с куколкой в руках и неосуществимое делается вероятным. Схожей «волшебной палочкой» имеет возможность стать оригами. Однако далековато не в любом целебном заведении отыщется специалист по куклотерапии, когда занятия оригами доступны фактически всем, правда и бумага имеется постоянно перед рукою. Оригами отлично используется в том числе и при аутизме.

В многих странах мира, где уже применяется оригами, утверждают, что такие занятия имеют позитивное влияние на эмоциональное состояние больных, снимают депрессию, увеличивают уверенность в личных силах, содействуют установлению дружественных контактов, которое делает лечение наиболее действенным и улучшает психическое состояние больных. Неповторимость арт-терапевтического воздействия оригами содержится еще в том, что даже при полной изоляции, человек может вести диалог с личным разумом, что приносит ему большое удовольствие.

Обобщая можно сказать, что сегодня художественная терапия и терапия искусством приобретает огромную популярность. 


\section{References}

[1] Kopytin A.I. Art therapy in a comprehensive school. Toolkit. St. Petersburg: Academy of Postgraduate Pedagogical Education, 2005.

[2] Semenyuk, L.M. Psychological features of aggressive behavior of adolescents and the conditions for its correction [Text] / M .: Flint, 2008. - p. 65. 